\title{
PRODUÇÃO E DISTRIBUIÇÃO DA MATÉRIA SECA DO PEPINO PARA CONSERVA EM DIFERENTES POPULAÇÕES DE PLANTAS ${ }^{1}$
}

\author{
DRY MATTER ACCUMULATION AND PARTITIONING OF PICKLING CUCUMBER PLANTS \\ UNDER DIFFERENT PLANT DENSITIES
}

\author{
Jacques Leandro Schvambach $^{2}$ Jerônimo Luiz Andriolo ${ }^{3}$ Arno Bernardo Heldwein ${ }^{4}$
}

RESUMO

\begin{abstract}
O trabalho teve como objetivo determinar o efeito da população de plantas na acumulação e distribuição da matéria seca entre as partes vegetativas e os frutos de plantas de pepino tipo conserva. Os experimentos foram realizados em uma estufa de polietileno, em populações de plantio de 2,00; 2,50, 3,33 e 5,00 plantas $m^{-2}$ na primavera de 1999 e de 4,00; 5,00; 6,66 e 10,00 plantas $m^{-2}$ no verão-outono de 2000. As plantas foram dispostas em fileiras distanciadas de um metro e tutoradas com fitas plásticas verticais. Determinou-se a evolução semanal da acumulação de matéria seca do caule, folhas e frutos. Os frutos foram colhidos diariamente e a matéria seca diária foi somada para obter o valor semanal acumulado. No primeiro experimento, houve resposta positiva da maior população tanto sobre a produção de matéria seca vegetativa como de frutos. A fração média da matéria seca total alocada para os frutos foi de $49,5 \%$, independente da população de plantas. No segundo experimento, houve efeito significativo da maior população apenas sobre a acumulação de matéria seca do caule e a fração alocada para os frutos decresceu com o aumento da população. No primeiro experimento, o rendimento acumulado de frutos respondeu linearmente ao aumento da população de plantas. No segundo experimento, essa resposta não foi observada. Concluiuse que não é possível recomendar uma única população de plantas a ser empregada ao longo do ano para o cultivo do pepino para conserva.
\end{abstract}

Palavras-chave: Cucumis sativus, crescimento, rendimento, eficiência de conversão, radiação, alocação da matéria seca.

\section{SUMMARY}

The aim of this work was to determine the effect of plant density on dry matter accumulation and distribution to fruits of pickling cucumber plants. Experiments were carried out inside a polyethylene greenhouse, where plants were grown in densities of 2.00, 2.50, 3.33 and 5.00 plants $m^{-2}$ in spring 1999, and of 4.00, 5.00, 6.66 and 10.00 plants $\mathrm{m}^{-2}$ in summer-autumn 2000 , in order to determine the effect of plant density on dry matter accumulation and partitioning between vegetative parts and fruits. Plants grew in rows and were trained according to the high-wire system. Dry matter accumulation of stem, leaves and fruits was measured weekly. Fruits were harvested daily, the dry matter measured and values were summed together to determine the cumulative week weight. In the first experiment, a positive effect of the higher plant density was observed on dry matter accumulation of shoot and fruits, with a mean fraction of $49.5 \%$ allocated to fruits. In the second experiment, this effect was recorded only on the stem and the fraction of dry matter allocated to fruits decreased when plant density changed from four to 10 plants. $m^{-2}$. Cumulative fruit yield in the first experiment showed a linear response to plant density while in the second experiment no effect of this variable was observed on fruit yield. It was concluded that it is not possible to use a pre-fixed plant density all over the year for the commercial production of pickling cucumber crops.

Key words: Cucumis sativus, growth, yield, growth efficiency, radiation, dry matter allocation.

\section{INTRODUÇÃO}

A evolução observada na olericultura brasileira nos últimos anos mostra tendência a um aumento do consumo de produtos processados com maior valor agregado (COSTA, 2000). Dentre as hortaliças consumidas em conserva, o pepino é uma das mais importantes. No Sul do Brasil, o cultivo dessa espécie para produção de frutos destinados a industrialização é realizado predominantemente de forma tutorada, empregando-se híbridos ginóicos

\footnotetext{
${ }^{1}$ Trabalho financiado com recursos da FAPERGS - Fundação de Amparo à Pesquisa do Estado do Rio Grande do Sul

${ }^{2}$ Engenheiro Agrônomo, Aluno do Programa de Pós-graduação em Agronomia, Universidade Federal de Santa Maria (UFSM), bolsista CAPES.

${ }^{3}$ Engenheiro Agrônomo, Professor Titular, Doutor, Departamento de Fitotecnia (DF), UFSM. 97105-900, Santa Maria, RS. E-mail: andriolo@creta.ccr.ufsm.br. Autor para correspondência.

${ }^{4}$ Engenheiro Agrônomo, Professor Titular, Doutor, DF, UFSM. 
com elevado potencial de rendimento de frutos (ESPINOLA, 2000).

A população de plantas ideal a ser empregada é aquela suficiente para atingir o índice de área foliar (IAF) ótimo a fim de interceptar o máximo de radiação solar útil à fotossíntese e ao mesmo tempo maximizar a fração da matéria seca alocada para os frutos. A população de plantas afeta a penetração da radiação solar no dossel e o equilíbrio entre o crescimento das partes vegetativas e dos frutos. Modificações na eficiência das fontes, através de uma alteração na população de plantas ou do aumento da disponibilidade de radiação, afetam indiretamente a distribuição da matéria seca entre os órgãos da planta. Esse efeito ocorre de forma indireta, mediante alterações no número de frutos em crescimento, os quais modificam a capacidade de dreno da planta (MARCELIS, 1993b; HEUVELINK, 1996, HAO \& PAPADOPOULOS, 1998).

O manejo da cultura do pepino para conserva tem como objetivo principal maximizar o rendimento de frutos. Entretanto, a produção de frutos depende diretamente do compartimento vegetativo da planta, que é responsável pela produção dos assimilados. Para maximizar a produção de frutos é necessário, portanto, atingir a produção potencial de assimilados em nível da planta inteira e em seguida alocar para os frutos a maior fração possível desses assimilados. O manejo da produção e da distribuição dos assimilados pode ser feito através da população de plantas e da poda. Essas práticas interferem no equilíbrio entre o crescimento dos compartimentos vegetativo $\mathrm{e}$ generativo da planta.

O presente trabalho teve como objetivo determinar o efeito da população de plantas sobre a acumulação de matéria seca e sua distribuição entre as partes vegetativas e os frutos de pepino tipo conserva em cultivo tutorado. Inferências são feitas apontando critérios de manejo a serem adotados na produção comercial dessa espécie.

\section{MATERIAL E MÉTODOS}

Dois experimentos foram conduzidos na área experimental do Departamento de Fitotecnia da Universidade Federal de Santa Maria, RS (latitude de $29^{\circ} 42^{\prime} \mathrm{S}$, longitude $53^{\circ} 48^{\prime} \mathrm{W}$ e altitude $95 \mathrm{~m}$ ) em estufa tipo Pampeana, de $240 \mathrm{~m}^{2}(24 \mathrm{mx} 10 \mathrm{~m})$, coberta com polietileno de baixa densidade e orientada no sentido norte-sul. Foi utilizado o híbrido Marinda, considerado como material vegetal de produção precoce, hábito de florescimento ginóico e frutos partenocárpicos.
No experimento 1, as mudas foram produzidas em bandejas de poliestireno, empregando substrato comercial. A semeadura foi efetuada no dia 09 de setembro de 1999 e o plantio no interior da estufa 20 dias após, quando as mudas estavam no estádio de duas folhas definitivas. A duração do período experimental foi de 64 dias, contados do transplante até o final da colheita dos frutos. $\mathrm{O}$ experimento 2 iniciou no dia 17 de fevereiro de 2000, efetuando-se a semeadura diretamente no solo no interior da estufa. A duração do período experimental foi de 52 dias, contados do estádio de duas folhas definitivas até o final da colheita dos frutos. A adubação foi efetuada de acordo com os resultados da análise de solo e as recomendações da COMISSÃO DE FERTILIDADE DO SOLO DOS ESTADOS DO RS/SC (1995). A irrigação foi feita por gotejamento, mantendo-se o potencial matricial do solo em valores superiores a $-0,0278 \mathrm{MPa}$, medido através de tensiômetros instalados entre as plantas dentro da área experimental e a $0,10 \mathrm{~m}$ de profundidade (CARON, 1999).

A condução das plantas foi feita verticalmente através de uma fita plástica, até aproximadamente, $2,30 \mathrm{~m}$ de altura, em haste única e com eliminação de todas as brotações axilares. Os tratamentos foram constituídos por diferentes populações de plantas, sendo de 2,00; 2,50; 3,33 e 5,00 plantas $\mathrm{m}^{-2}$ no experimento 1 e de 4,00; 5,00; 6,66 e 10,00 plantas $\mathrm{m}^{-2}$ no experimento 2. O delineamento experimental empregado foi de blocos ao acaso, com quatro tratamentos e quatro repetições. Cada um dos blocos foi constituído por uma fileira de plantas, com espaçamento de $1,0 \mathrm{~m}$ entre as fileiras. Cada parcela foi formada por $20 \mathrm{e}$ 23 plantas nos experimentos 1 e 2 , respectivamente. $\mathrm{O}$ efeito dos tratamentos foi medido através da análise do crescimento das plantas, mediante a determinação da matéria seca (MS) dos órgãos da parte aérea e da área foliar, feitas semanalmente à partir do início da floração até o final da colheita de frutos. Para determinar a MS, foram coletadas semanalmente quatro plantas por tratamento, escolhidas por sorteio, uma em cada parcela. As plantas nas bordaduras das parcelas e das coletas anteriores não foram empregadas para efetuar determinações. Imediatamente após a coleta, as plantas foram separadas em três frações: caule (incluindo pecíolos e pedúnculos), folhas verdes e frutos, que foram submetidas à secagem em estufa à temperatura de $60^{\circ} \mathrm{C}$, até peso constante. Uma amostra de folhas representativa da área foliar da planta foi utilizada para determinar a SLA (superfície população específica), pela medida da MS de discos foliares de área igual $0,5026 \mathrm{~cm}^{2}$, 
extraídos dessas folhas. Uma relação foi estabelecida entre a MS e a superfície dos discos, que foi empregada para estimar a área foliar da planta inteira através da MS total das folhas.

A colheita de frutos foi feita diariamente, coletando-se aqueles que apresentavam um comprimento entre três e sete centímetros, efetuando-se a seguir a contagem e determinação da massa fresca (MF). No experimento 1, a estimativa da MS dos frutos colhidos verdes foi feita multiplicando-se a MF pelo teor de MS dos frutos da coleta semanal de plantas feita para determinação da MS. No experimento 2, uma amostra de frutos com MF variando entre 100 e $200 \mathrm{~g}$ foi submetida a secagem a $60^{\circ} \mathrm{C}$, até peso constante, para determinar o teor de MS em cada colheita de frutos. Para determinar a produção acumulada de MS em cada uma das coletas semanais efetuadas, a MS dos frutos colhidos diariamente a partir da coleta anterior foi acrescentada ao valor da MS dos frutos existentes sobre a planta no dia de cada coleta.

A radiação solar global incidente $(\mathrm{Rg})$ foi estimada pela insolação diária segundo o modelo proposto por Ångström, com os coeficientes ajustados para Santa Maria por ESTEFANEL et al., (1990), corrigida pelo coeficiente de transmissividade da estufa, considerado igual a 0,73 (BURIOL et al., 1995). Os dados de insolação diária foram obtidos na Estação Climatológica do Departamento de Fitotecnia, localizada a aproximadamente 100 metros ao sul da área experimental. A temperatura foi registrada por um termohigrógrafo instalado no interior de um abrigo a $1,5 \mathrm{~m}$ de altura, no centro da estufa. A temperatura média diária foi obtida através da média dos valores observados a cada duas horas durante as 24 horas do dia.

\section{RESULTADOS E DISCUSSÃO}

A média diária da radiação solar estimada no interior da estufa nos experimentos foi de 12,8 MJ m ${ }^{-2}$ dia $^{-1}$ no experimento 1 e de $9,9 \mathrm{MJ} \mathrm{m}^{-2} \mathrm{dia}^{-1}$ no experimento 2 , o que representou uma diferença de $29 \%$. Os valores acumulados durante o mesmo período foram de $829 \mathrm{MJ} \mathrm{m}^{-2}$ e $567 \mathrm{MJ} \mathrm{m}^{-2}$ respectivamente. No experimento 1 , os valores diários da radiação solar aumentaram no decorrer do ciclo da cultura, enquanto no experimento 2 ocorreu o inverso. Dinâmica semelhante foi observada com a temperatura média (Tm) do ar. No experimento 1, a Tm diária foi menor que $20^{\circ} \mathrm{C}$ até 20 dias após o plantio (DAP) e em seguida manteve-se dentro dos limites entre $20^{\circ} \mathrm{C}$ e $25^{\circ} \mathrm{C}$, até o final do ciclo da cultura. No experimento 2, foram observados valores entre $24^{\circ} \mathrm{C}$ e $29^{\circ} \mathrm{C}$ no período até $18 \mathrm{DAP}$, decrescendo a seguir até atingir valores inferiores a $20^{\circ} \mathrm{C}$ a partir dos 44 DAP. A Tm de todo o período experimental foi de $20,6^{\circ} \mathrm{C}$ e $21,7^{\circ} \mathrm{C}$, nos experimentos 1 e 2 , respectivamente.

As curvas ajustadas da evolução da produção de matéria seca total em nível da planta inteira foram do tipo polinomial, com coeficientes de determinação superiores a 0,98 nas quatro populações e em ambos os experimentos (Figuras 1a,b). Os valores acumulados na última coleta nas populações mais elevadas dos dois experimentos mostraram diferenças significativas em relação às populações inferiores (Tabela 1).

A matéria seca da fração vegetativa da planta cresceu linearmente durante o período de duração do experimento 1 , com coeficientes de determinação superiores a 0,98 nos quatro tratamentos (Figura 2a). Quanto aos frutos, a evolução ocorreu segundo um modelo polinomial, com coeficientes de determinação superiores a 0,99
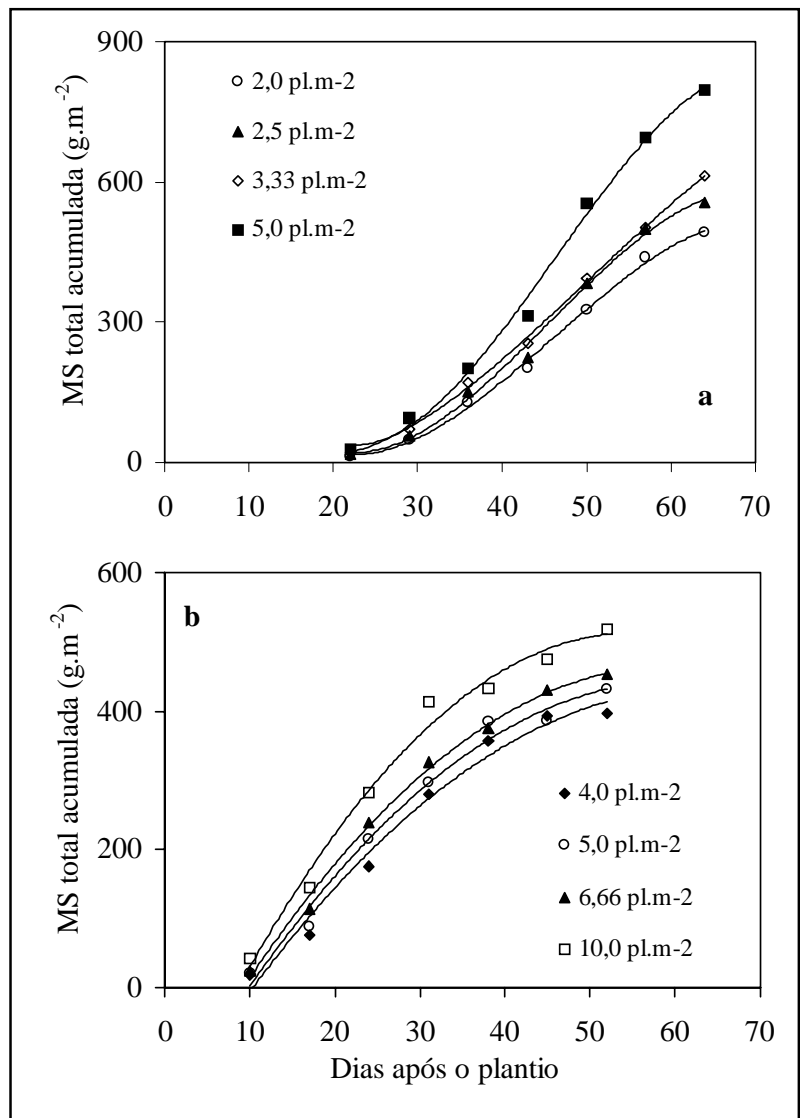

Figura 1 - Matéria seca (MS) total acumulada em plantas de pepino tipo conserva em diferentes populações de plantas, na primavera (a) e no verão-outono (b). Santa Maria, UFSM, $1999 / 2000$. 
Tabela 1 - Índice de área foliar máximo (IAF), produção e distribuição da matéria seca total na última coleta de plantas de pepino para conserva em função da população de plantas, na primavera (experimento 1) e no verão-outono (experimento 2). Santa Maria, UFSM, 1999/2000.

\begin{tabular}{ccccc}
\hline $\begin{array}{c}\text { População de } \\
\text { plantas } \\
\left(\mathrm{pl} \mathrm{m} \mathrm{m}^{-2}\right)\end{array}$ & IAF & Matéria seca total $\left(\mathrm{g} . \mathrm{m}^{-2}\right)$ & $\begin{array}{c}\text { Fração da matéria seca } \\
\text { total }(\%)\end{array}$ \\
\cline { 2 - 5 } & & Caule Folhas Frutos & Total Caule Folhas Frutos
\end{tabular}

Experimento 1

$\begin{array}{clrllllll}2,0 & 1,89 \mathrm{c} & 92 \mathrm{c} & 157 \mathrm{~b} & 241 \mathrm{c} & 490 \mathrm{c} & 18,8 \mathrm{a} & 32,0 \mathrm{a} & 49,2 \mathrm{a} \\ 2,5 & 2,28 \mathrm{bc} & 102 \mathrm{c} & 178 \mathrm{~b} & 275 \mathrm{bc} & 556 \mathrm{~b} & 18,4 \mathrm{a} & 32,0 \mathrm{a} & 49,6 \mathrm{a} \\ 3,33 & 2,78 \mathrm{~b} & 120 \mathrm{~b} & 196 \mathrm{ab} & 295 \mathrm{~b} & 611 \mathrm{~b} & 19,6 \mathrm{a} & 32,1 \mathrm{a} & 48,3 \mathrm{a} \\ 5,0 & 3,73 \mathrm{a} & 153 \mathrm{a} & 238 \mathrm{a} & 404 \mathrm{a} & 796 \mathrm{a} & 19,3 \mathrm{a} & 29,9 \mathrm{a} & 50,8 \mathrm{a}\end{array}$

Experimento 2

$\begin{array}{lllllllll}4,0 & 5,49 \mathrm{~b} & 115 \mathrm{c} & 101 \mathrm{a} & 179 \mathrm{a} & 397 \mathrm{~b} & 29,1 \mathrm{~b} & 25,6 \mathrm{a} & 45,3 \mathrm{a} \\ 5,0 & 5,39 \mathrm{~b} & 130 \mathrm{bc} & 115 \mathrm{a} & 186 \mathrm{a} & 432 \mathrm{~b} & 30,2 \mathrm{~b} & 26,6 \mathrm{a} & 43,2 \mathrm{a} \\ 6,66 & 6,36 \mathrm{~b} & 159 \mathrm{~b} & 116 \mathrm{a} & 176 \mathrm{a} & 453 \mathrm{~b} & 35,2 \mathrm{a} & 25,8 \mathrm{a} & 39,0 \mathrm{ab} \\ 10,0 & 8,80 \mathrm{a} & 197 \mathrm{a} & 143 \mathrm{a} & 177 \mathrm{a} & 518 \mathrm{a} & 38,1 \mathrm{a} & 27,7 \mathrm{a} & 34,2 \mathrm{~b}\end{array}$

Médias não seguidas de mesma letra na coluna diferem significativamente pelo teste de Duncan em nível de $5 \%$ de probabilidade de erro.

nas quatro populações, indicando tendência de decréscimo nas taxas de acumulação ao final do período experimental e valores mais elevados na

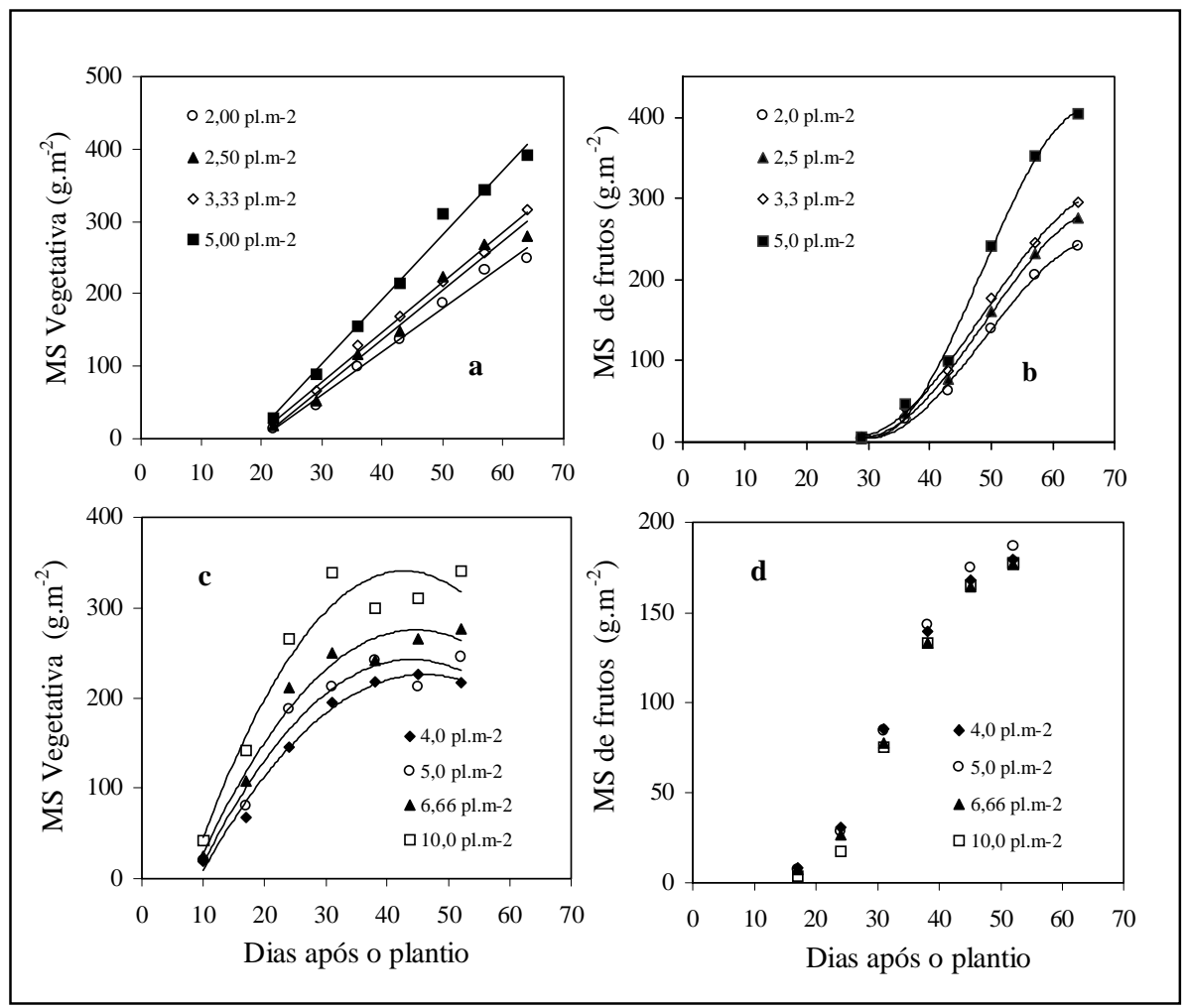

Figura 2 - Matéria seca (MS) da parte vegetativa $(a, c)$ e de frutos $(b, d)$ de plantas de pepino tipo conserva em diferentes populações de plantas, na primavera $(a, b)$ e no verão-outono (c,d). Santa Maria, UFSM, 1999/2000. maior população (Figura 2b). As médias na última coleta efetuada confirmaram essa tendência, com diferenças significativas entre a média da população mais elevada e as demais, nos três órgãos avaliados (Tabela 1). No experimento 2 (Figuras 2c,d), a acumulação de matéria seca vegetativa ocorreu segundo um modelo quadrático, com taxas de acumulação negativas nas últimas coletas. Os coeficientes de determinação foram de 0,98 na menor população e de 0,94 na maior delas e os valores medidos na última coleta mostraram diferenças significativas apenas para o caule (Tabela 1). Quanto aos frutos, a evolução ocorreu segundo um modelo polinomial e os quatro tratamentos mostraram tendência similar, confirmada pela não significância das diferenças entre as médias na última coleta efetuada (Tabela 1). A fração da matéria seca alocada para os frutos não mostrou diferença significativa entre os tratamentos do experimento 1 , com valor médio de $49,5 \%$. No experimento 2, essa fração foi menor e decresceu com o aumento da população, atingindo o valor mais baixo de $34,2 \%$ na população de 10 plantas $\mathrm{m}^{-2}$. O índice de área foliar (IAF), nos dois experimentos, respondeu de forma linear ao aumento da população de plantas (Tabela 1).

Tem sido demonstrada, na literatura, a existência de uma relação entre a acumulação de matéria seca pelas culturas de hortaliças e a quantidade de radiação solar recebida durante o ciclo de crescimento (COCKSHULL et al., 1992; GARY et al.,

Ciência Rural, v. 32, n. 1, 2002. 
1996; CHALLA \& BAKKER, 1998). A conversão da energia em biomassa depende da sua intercepção e, por esse motivo, a eficiência de conversão aumenta com o aumento da área foliar, até atingir a saturação. No experimento 1 , a eficiência de conversão da radiação em matéria seca total da planta foi de $0,59 \mathrm{gMS} \mathrm{MJ}^{-1}$ de $\mathrm{Rg}$ dentro da estufa na população de duas plantas $\mathrm{m}^{-2} \mathrm{e}$ aumentou linearmente $(\mathrm{y}=\mathrm{ax}+\mathrm{b})$ com a população até atingir o valor de $0,96 \mathrm{gMS} \mathrm{MJ}^{-1}$, com coeficiente $a$ igual a $0,1205\left(R^{2}=0,99\right)$. No experimento 2 , essa eficiência foi de $0,70 \mathrm{gMS} \mathrm{MJ}^{-1}$ de $\mathrm{Rg}$ na população de quatro plantas $\mathrm{m}^{-2}$ e também aumentou linearmente com a população, até atingir o valor de $0,91 \mathrm{gMS} \mathrm{MJ}^{-1}$. Porém, a resposta da eficiência de conversão ao aumento da população foi menor, com coeficiente $a$ do modelo linear igual a $0,0334\left(\mathrm{R}^{2}=0,98\right)$. Esses valores se situam abaixo daqueles constatados em plantas de pepino tipo salada por MARCELIS (1993a,b; 1994a) e também em tomateiro por DE KONING (1993) e HEUVELINK (1996), todos próximos de 1,40gMS $\mathrm{MJ}^{-1}$ de $\mathrm{Rg}$ global.

Quando analisados separadamente, os órgãos da planta mostraram eficiências de conversão distintas. No experimento 1, a eficiência, tanto do compartimento vegetativo como dos frutos, aumentou de $0,30 \mathrm{gMS} \mathrm{MJ}^{-1}$ na menor população para $0,48 \mathrm{gMS} \mathrm{MJ}^{-1}$, aproximadamente, na população de cinco plantas $\mathrm{m}^{-2}$. Não foi constatada saturação dessa variável por efeito do incremento da população da cultura. No experimento 2, o compartimento vegetativo e os frutos apresentaram resposta diferenciada a esta variável. O primeiro passou de $0,38 \mathrm{gMS} \mathrm{MJ}^{-1}$ na menor população para 0,60 , na população de 10 plantas $\mathrm{m}^{-2}$, enquanto os frutos mostraram uma eficiência próxima de $0,32 \mathrm{gMS} \mathrm{MJ}^{-1}$ nas quatro populações.

As variações observadas na eficiência de conversão da radiação solar em matéria seca, entre diferentes populações, entre diferentes órgãos e também entre os experimentos sugerem a existência de interações com os elementos do ambiente. No experimento 1 , o aumento da disponibilidade de radiação solar no decorrer do experimento foi interceptado pela cultura à medida que houve o crescimento da área foliar, em consequiência de uma maior população de plantas. Nesse caso, para cada fração extra de matéria seca total sintetizada, a distribuição dessa fração entre o compartimento vegetativo e os frutos ocorreu segundo uma proporção aproximadamente constante. Esse fato fica demonstrado pela figura $3 \mathrm{a}$, na qual a relação entre a evolução da matéria seca entre esses dois compartimentos se ajustou a um modelo linear semelhante nas quatro populações. Porém, no

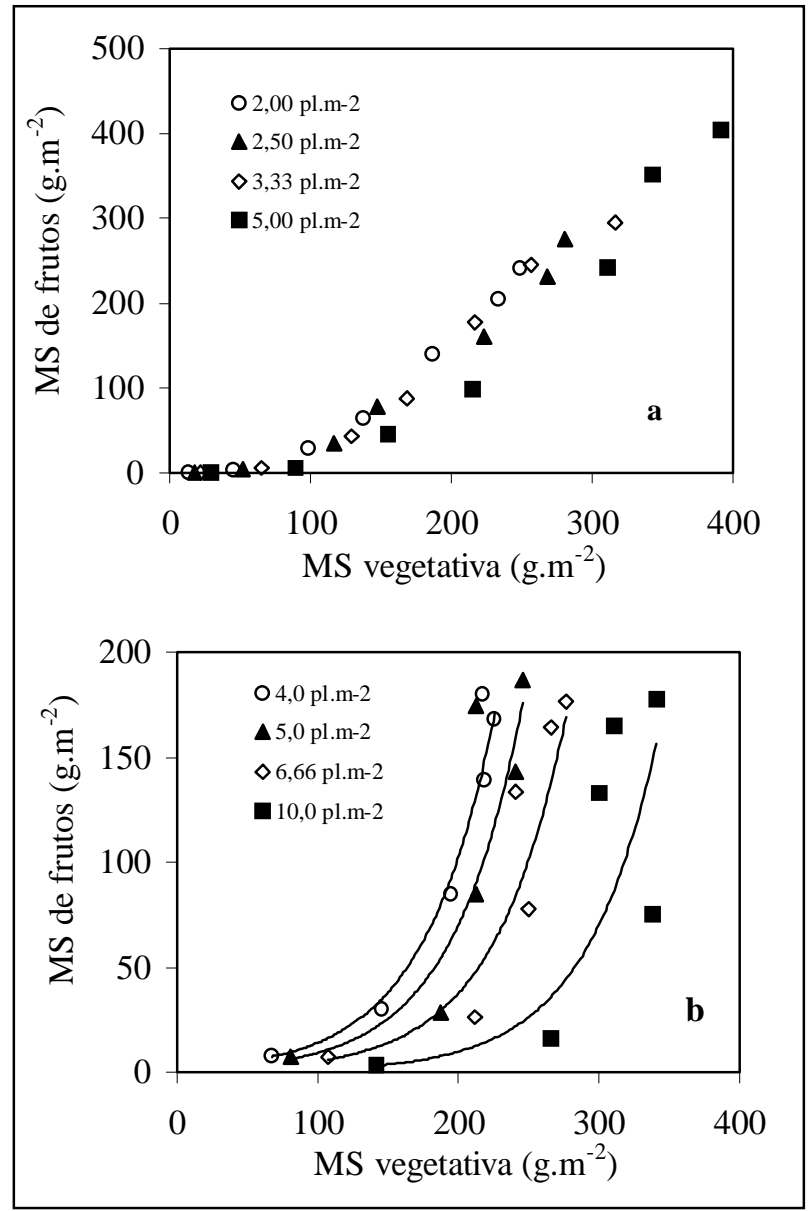

Figura 3 - Relação entre a evolução da matéria seca (MS) da parte vegetativa e de frutos de plantas de pepino tipo conserva em diferentes populações de plantas, na primavera (a) e no verão-outono (b). Santa Maria, UFSM, 1999/2000.

experimento 2, o aumento da população de plantas também induziu uma maior intercepção de radiação, que ficou acumulada no compartimento vegetativo, como demonstrado pelas distintas curvas referentes a cada uma das populações comparadas. Esses resultados confirmam observações anteriores de WIDDERS \& PRICE (1989) e MARCELIS (1994a), que verificaram um aumento na fração vegetativa de plantas de pepino tipo salada em função do aumento da população de plantas e da intensidade de sombreamento, respectivamente. Entretanto, em cada população, os frutos mostraram prioridade na distribuição da matéria seca, como pode ser visualizado pelo modelo exponencial das curvas referentes a sua evolução no decorrer do experimento (Figura 3b). Foi demostrado anteriormente em tomateiro, que essa forma de distribuição da matéria seca é característica de períodos em que a disponibilidade de radiação solar passa a ser limitante (ANDRIOLO et al., 1998). 
Porém, a falta de resposta da eficiência de conversão da radiação pelos frutos ao aumento da área foliar sugere limitações na força de dreno da planta. Esses resultados indicam que a radiação solar não é a única variável a determinar o rendimento da cultura, existindo outras interações que também devem ser consideradas para estimar corretamente o rendimento potencial das hortaliças em diferentes condições ambientais.

A resposta tanto do rendimento de frutos como do crescimento vegetativo ao aumento da população de plantas não foi idêntico nos dois experimentos. No experimento 1 , o rendimento de frutos $\mathrm{e} o$ crescimento vegetativo mostraram resposta linear até a população de cinco plantas. $\mathrm{m}^{-2}$, indicando a necessidade de efetuar novos experimentos para determinar o limite acima do qual não mais é observada resposta dessas variáveis à população de plantas (Figura 4a). Entretanto, no experimento 2, populações mais elevadas não mostraram efeito sobre a produção de frutos (Figura 4b). Para fins de produção comercial com essa cultura, os resultados indicam que não é possível recomendar uma população de plantas única a ser empregada nos diferentes cultivos realizados ao longo do ano.

Os modelos empregados para indicar as tendências de evolução da acumulação da matéria seca no decorrer dos dois experimentos evidenciaram elevado coeficiente de determinação em todas as populações estudadas. Esse fato indica que essa variável poderá vir a ser incorporada nos modelos de crescimento e desenvolvimento para essa cultura, já existentes na literatura (MARCELLIS, 1994b; PUERTO et al., 2000) ou que vierem a ser desenvolvidos nos próximos anos. Os modelos atuais utilizam valores fixos de população de plantas e os resultados mostrados nesse trabalho indicam que essa variável deve ser adaptada de acordo com as condições ambientais e o manejo da cultura. Esses resultados levantam também dúvidas sobre a adequação dos métodos para estimar o desenvolvimento das hortaliças com base unicamente na soma térmica acumulada durante o ciclo de desenvolvimento, como tem sido empregado para outras espécies como os cereais. Os dois experimentos mostraram respostas diferentes da cultura, embora a temperatura média no decorrer de cada um dos períodos experimentais tenha diferido apenas $1,1^{\circ} \mathrm{C}$. É pouco provável que o efeito da temperatura sobre a força de dreno seja o mesmo quando valores baixos dessa variável do ambiente ocorrerem no estádios iniciais ou finais do ciclo, quando o compartimento generativo representado pelos frutos passa a ter importância preponderante na repartição da matéria seca.

\section{CONCLUSÃO}

A acumulação de matéria seca em nível da planta inteira responde ao aumento da população de plantas do pepino para conserva. O padrão de repartição da matéria seca acumulada entre os órgãos da parte aérea da planta não é constante, influenciando o rendimento de frutos. Consequentemente, não é possível recomendar uma única população de plantas a ser empregada ao longo do ano para essa cultura.

\section{REFERÊNCIAS BIBLIOGRÁFICAS}

ANDRIOLO, J.L.; STRECK, N.A.; BURIOL, G.A., $\boldsymbol{e t} \boldsymbol{a l}$. Growth, development and dry matter distribution of a tomato crop as affected by environment. Journal of Horticultural Science \& Biotechnology, Ashford Kent, v.73, n.1, p.125130, 1998.

BURIOL, G.A.; STRECK, N.A.; PETRY, C., $\boldsymbol{e}$ t al. Transmissividade a radiação solar do polietileno de baixa população utilizado em estufas. Ciência Rural, Santa Maria, v.25, n.1 p.1-4, 1995.

CARON, B.O. Consumo d'água e coeficiente de cultura do meloeiro cultivado em estufa plástica. Santa Maria-RS, 1999. 71p. Dissertação (Mestrado em Agronomia) Programa de Pós-graduação em Agronomia, Universidade Federal de Santa Maria, 1999.

CHALLA, H.; BAKKER, J. Potential production within the greenhouse environment.. In: ENOCH, Z., STANHILL, G. (Eds.). Ecosystems of the world. The greenhouse ecosystem. Amsterdan: Elsevier, 1998. p.333-348.
Figura 4 - Matéria seca (MS) da fração frutos (a) e vegetativa (b) de plantas de pepino tipo conserva em função da população de plantas, na primavera (1) e no verão-outono (2). Santa Maria, UFSM, 1999/2000. (ya1 = 52,959x + 134,53, $\mathrm{R}^{2}=0,98 ; \mathrm{ya} 2=-0,8832 \mathrm{x}+185,75, \mathrm{R}^{2}=0,26 ; \mathrm{yb} 1=46,686 \mathrm{x}+159,76, \mathrm{R}^{2}$ $\left.=0,99 ; \mathrm{yb} 2=20,123 \mathrm{x}+141,0, \mathrm{R}^{2}=0,99\right)$. 
COCKSHULL, K.E.; GRAVES, C.J.; CAVE, C.R.J. The influence of shading on yield of glasshouse tomatoes. Journal of Horticultural Science, Ashford, v.67, p.11-24, 1992.

COMISSÃO DE FERTILIDADE DO SOLO DOS ESTADOS DO RS E SC. Recomendações de adubação e calagem para os Estados do Rio Grande do Sul e Santa Catarina. 3. ed. Passo Fundo : SBCS - Núcleo Regional Sul/CNPT/EMBRAPA, 1995. 224p.

COSTA, C.P. da. Olericultura Brasileira: passado, presente e futuro. In: CONGRESSO BRASILEIRO DE OLERICULTURA, 40, CONGRESSO IBEROAMERICANO SOBRE A UTILIZAÇÃO DE PLÁSTICOS NA AGRICULTURA, 2, SIMPÓSIO LATINOAMERICANO DE PRODUÇÃO DE PLANTAS MEDICINAIS, AROMÁTICAS E CONDIMENTARES, 1, 2000. São Pedro, SP. Trabalhos apresentados e palestras... Horticultura Brasileira, Brasília : SOB/FCAV-UNESP, 2000. v. 18 , p.7 - 11. Suplemento.

DE KONNING, A.N.M. Development and dry matter distribution in glasshouse tomato: a quantitative approach. Wageningen - NL, 1994. 240p. Dissertation, Wageningen Agricultural University, 1994.

ESPINOLA, H.N.R. Efeito de três doses de nutrientes minerais sobre a acumulação de massa seca e nitrogênio pela planta de pepino tipo conserva. Santa Maria-RS. 2000. 52p. Dissertação (Mestrado em Agronomia) Programa de Pós-graduação em Agronomia Universidade Federal de Santa Maria, 2000.

ESTEFANEL, V.; SCHNEIDER, F.M.; BERLATO, M.A., $\boldsymbol{e}$ t al. Insolação e radiação solar na região de Santa Maria, RS. I Estimativa da radiação solar global incidente a partir dos dados de insolação. Revista do Centro de Ciências Rurais, Santa Maria, v.20, n.3-4, p.203-218, 1990.

GARY, C.; BAILLE, A.; NAVARRETE, M., et al. TOMPOUSSE, un modèle simplifié de prévision du rendement et du calibre de la tomate. In: SÉMINAIRE DE L'AIP “SERRES”. 1996, Alenya. Proceedings... Alenya: INRA, 1996, 10p
HAO, X.; PAPADOPOULOS, A.P. Effects of supplemental lighting and cover materials on growth, photosynthesis, biomass partitioning, early yield and quality of greenhouse cucumber. Scientia Horticulturae, Amsterdan, v.80, p.1 $18,1999$.

HEUVELINK, E. Tomato growth and yield: quantitative analysis and synthesis. Wageningen-NL. 1996. 326p. Dissertation. Wageningen Agricultural University, 1996.

MARCELIS, L.F.M. Fruit growth and biomass allocation to the fruits in cucumber. 1. effect of fruit load and temperature. Scientia Horticulturae, Amsterdan, v.54, p.107-121, 1993a.

MARCELIS, L.F.M. Fruit growth and biomass allocation to the fruits in cucumber. 2. effect of irradiance. Scientia Horticulturae, Amsterdan , v.54, p.123-130, 1993 b.

MARCELIS, L.F.M. Effect of fruit growth, temperature and irradiance on biomass allocation to the vegetative parts of cucumber. Netherlands Journal of Agricultural Science, Wageningen, v.42, n.2, p.115-123, 1994a.

MARCELIS, L.F.M. A simulation model for dry matter partitioning in cucumber. Annals of Botany, Oxford, v.74, p.43-52, 1994 b.

PUERTO, H.M.; LÓPEZ, J.C.; GALLARDO, M., $\boldsymbol{e}$ t al Modeling biomass production of a greenhouse cucumber crop. In: INTERNATIONAL SYMPOSIUM ON PROTECTED CULTIVATION IN MILD WINTER CLIMATES: CURRENT TRENDS FOR SUSTAINABLE TECHNOLOGIES, 2000, Cartagena, Espanha. Book of Abstracts... Cartagena : ISHS, v.1, 2000. p.35.

WIDDERS, I.E.; PRICE, H.C. Effect of plant density on growth and biomass partitioning in pickling cucumbers. Journal American Society Horticulturae Science, Mount Vernon, v.114, n.5, p.751-755, 1989. 